\title{
Frequency of Betel nut Addiction in Pregnant Anaemic Women and its impact on fetal outcome
}

\author{
Farkhunda Khursheed, Chandra Madhudas
}

\begin{abstract}
OBJECTIVE: To determine the frequency of betel nut addiction in pregnant anaemic women and to find out its association with adverse pregnancy outcome.

METHODOLOGY: This observational study was conducted in the department of Obstetrics \& Gynaecology unit 2 at Liaquat University of Medical \& Health Sciences Jamshoro from January to June 2015. All the pregnant women admitted in ward or labour room for delivery with $\mathrm{Hb} \%<11 \mathrm{gm} / \mathrm{dl}$ during the study period were included. Those having history of antepartum haemorrhage, preeclampsia, eclampsia, chorioamnionitis or any medical disorder except anaemia were excluded. The frequency of betel nut consumption was calculated. The frequency of addiction in different age groups, parity and population (rural/urban) was determined. The association of addiction with severity of anaemia and adverse fetal outcome (perinatal deaths, low birth weight infants, preterm deliveries) was also determined.

RESULTS: A total of 1700 women were included. Out of these, 1120 women $(65.88 \%)$ were found having history of betel nut consumption. The frequency of addiction was highest in the age group of 25-35 $(69.83 \%)$, para $2-5(68.17 \%)$ and in women belonged from rural area $(77.49 \%)$. History of addiction was found in $66.15 \%(n=260)$ cases of fetal death, $71 \%(n=169)$ cases of low birth weight infants and $68.59 \%(n=121)$ cases of preterm deliveries.

CONCLUSION: It is concluded that betel nut consumption among pregnant women is very high in our community. It is also determined that these products are positively associated with adverse pregnancy outcome.
\end{abstract}

KEY WORDS: Pregnancy, betel nut addiction, anaemia, fetal outcome

This article may be cited as: Khursheed F, Madhudas C. Frequency of Betel nut Addiction in Pregnant Anaemic Women and its impact on fetal outcome. J Liaquat Uni Med Health Sci. 2017;16 (03):145-8. doi: 10.22442/jlumhs.171630523

\section{INTRODUCTION}

Anaemia is the most widespread medical disorder in the world. It is a global health problem and pregnant women are the most vulnerable group. According to a study in 2011, the world wide prevalence of anemia in pregnant women was $38 \%{ }^{1}$ and in developing countries it was more than $50 \%{ }^{2,3}$. The etiology of anemia among pregnant women in developing countries is multifactor and varies by geographic region ${ }^{4}$. In the region of South East Asia, consumption of betel nut and its products (pan, supari, gutka, main-puri) is very much common in general population as well as by pregnant women. Its persistent use makes them addicted (physically or psychologically dependant on a habit forming substance) to these substances.

Betel nut or Areca catechu (Scientific name) is the seed of a fruit of a tropical palm tree. Betel nut chewing is an ancient tradition for millions of people across the South East Asian countries, while pan is restricted to Indian subcontinent like India, Pakistan and Bangladesh ${ }^{5}$. The consumption of betel nut has a highly addictive and abusive potential as strong as cigarette smoking. Its habitual and chronic daily use is well recognized with almost $50 \%$ of users consuming it on a daily basis ${ }^{6}$.

Betel nut is considered to be the $4^{\text {th }}$ most common psychoactive addiction in the world after tobacco, alcohol and caffeine ${ }^{7,8}$. Different studies have reported that women who chew betel nut formulation during pregnancy have increased risk of adverse pregnancy outcome such as anemia, miscarriage and adverse effects on fetus ${ }^{9}$. The effects were similar to those reported for consumption of alcohol and tobacco during pregnancy ${ }^{10}$.

It has been found that betel nut consumption with chewing tobacco is associated with folate deficiency and increase susceptibility to DNA damage ${ }^{6,11}$. Folate deficiency during pregnancy may lead to many adverse outcomes including neural tube defects, low birth weight, preterm birth, growth retardation and megaloblastic anemia ${ }^{6}$.

Thus the aim of this study was to determine the prevalence of addiction of betel nut formulation in pregnant women presented with anemia and to find out the association of this addiction with adverse 
pregnancy outcome.

\section{METHODOLOGY}

This was an observational study conducted in the department of Obstetrics and Gynaecology Unit 2 at Liaquat University of Medical and Health Sciences Jamshoro for a period of six months from January to June 2015. All the women admitted in the ward or labour room and delivered in hospital having hemoglobin $(\mathrm{Hb})$ less than $11 \mathrm{gm} / \mathrm{dl}$ were included in the study. Those presented with history of antepartum haemorrhage, preeclampsia, eclampsia, chorioamnionitis or any medical disorders except anaemia were excluded from the study. The required information was collected on a structured proforma designed for the study. The data pertaining to age, parity, locality (urban/rural) was obtained. According to age, women were divided into three groups, age below 25 years, between 25-35 years and above 35 years. According to parity they were divided as Para 0-1, Para 2-5 and Para $>5$. Anemia was categorized according to $\mathrm{WHO}$ classification as mild ( $\mathrm{Hb} 9-10.9 \mathrm{gm} / \mathrm{dl})$, moderate $(\mathrm{Hb}$ $7-8.9 \mathrm{gm} / \mathrm{dl})$ and severe $(\mathrm{Hb}<7 \mathrm{gm} / \mathrm{dl})$. The prevalence of consumption of betel nut and its formulation (pan, supari, gutka and main-puri) was determined in these women. Adverse pregnancy outcomes were observed in terms of fetal deaths (intrauterine / perinatal), low birth weight and preterm birth. Association of addiction with severity of anemia and adverse pregnancy outcomes was determined.

The software used to analyze data was Med Calc. The results presented in terms of frequencies and percentages. Chi square test was used for comparison of proportion, p-value $<0.05$ was considered significant.

\section{RESULTS}

A total of 1700 women were included in the study, having pregnancy with hemoglobin $<11 \mathrm{gm} / \mathrm{dl}$. Out of these 1700 anaemic women,1120 cases were found having history of addiction of betel nut or some of its products, giving a prevalence of $65.88 \%$ (Table I). The frequency of addicted women in three age and parity groups and in urban and rural population was presented in Table II. Out of 1700 cases of study sample, $511(30.05 \%)$ presented with mild degree of anemia, 783 (46.05\%) with moderate degree and 406 $(23.88 \%)$ with severe degree of anemia. Frequency of addicted women was high in those presented with moderate degree $(80.33 \%)$ and severe degree of anemia (69.95\%), (Table III). Regarding the fetal outcome, there were 260 (15.29\%) fetal deaths, 169 $(9.94 \%)$ low birth weight infants and $121(7.11 \%)$ preterm deliveries. History of addiction was found in $172(66.15 \%)$ cases of fetal death, $120(71 \%)$ cases of LBW infants and $83(68.59 \%)$ cases of preterm deliveries (Table IV).

\section{TABLE I: PREVALENCE OF BETEL NUT ADDICTION IN PREGNANT ANAEMIC WOMEN}

\begin{tabular}{|l|r|}
\hline Total number of pregnant anaemic women & 1700 \\
\hline No: of women with history of betel nut addiction & 1120 \\
\hline Prevalence (percentage) of betel nut addiction & $65.88 \%$ \\
\hline
\end{tabular}

TABLE II: DEMOGRAPHIC FEATURE

\begin{tabular}{|c|c|c|c|c|}
\hline Variable & $\begin{array}{c}\text { No: of } \\
\text { cases } \\
(n=1700)\end{array}$ & $\begin{array}{l}\text { Cases with } \\
\text { history of } \\
\text { addiction }\end{array}$ & $\begin{array}{c}\text { Percentage } \\
(\%)\end{array}$ & P-value \\
\hline $\begin{aligned} & \text { Age } \\
& \text { (Years) } \\
&<25 \\
& 25-35 \\
&>35\end{aligned}$ & $\begin{array}{l}270 \\
852 \\
578\end{array}$ & $\begin{array}{l}132 \\
595 \\
393\end{array}$ & $\begin{array}{l}48.88(n=270) \\
69.83(n=852) \\
67.99(n=419)\end{array}$ & $\begin{aligned} & 0.7523 \\
< & 0.0001 \\
< & 0.0001\end{aligned}$ \\
\hline $\begin{array}{l}\text { Parity } \\
\text { Primipara } \\
\text { Para 2-5 } \\
\text { Para }>5\end{array}$ & $\begin{array}{l}419 \\
751 \\
530\end{array}$ & $\begin{array}{l}267 \\
512 \\
341\end{array}$ & $\begin{array}{l}63.72(n=419) \\
68.17(n=751) \\
64.33(n=530)\end{array}$ & $\begin{array}{l}<0.0001 \\
<0.0001 \\
<0.0001\end{array}$ \\
\hline $\begin{array}{l}\text { Locality } \\
\text { Rural } \\
\text { Urban }\end{array}$ & $\begin{array}{l}813 \\
887\end{array}$ & $\begin{array}{l}630 \\
490\end{array}$ & $\begin{array}{l}77.49(n=813) \\
55.24(n=887)\end{array}$ & $\begin{array}{r}<0.0001 \\
0.0002\end{array}$ \\
\hline
\end{tabular}

TABLE III: SEVERITY OF ANAEMIA

\begin{tabular}{|c|c|c|c|c|}
\hline Variable & $\begin{array}{c}\text { No: of } \\
\text { cases } \\
(\mathbf{n = 1 7 0 0 )})\end{array}$ & $\begin{array}{c}\text { Cases with } \\
\text { history of } \\
\text { addiction }\end{array}$ & $\begin{array}{c}\text { Percentage } \\
(\%)\end{array}$ & P- value \\
\hline $\begin{array}{c}\text { Mild } \\
(\mathrm{Hb} \mathrm{9-10.9} \\
\text { g/dl) }\end{array}$ & 511 & 207 & $40.50(\mathrm{n}=511)$ & $<0.0001$ \\
\hline $\begin{array}{l}\text { Moderate } \\
(\mathrm{Hb} 7-8.9 \\
\text { g/dl) }\end{array}$ & 783 & 629 & $80.33(\mathrm{n}=783)$ & $<0.0001$ \\
\hline $\begin{array}{c}\text { Severe } \\
(\mathrm{Hb}<7 \mathrm{~g} / \mathrm{dl})\end{array}$ & 406 & 284 & $69.95(\mathrm{n}=406)$ & $<0.0001$ \\
\hline
\end{tabular}

TABLE IV: ADVERSE FETAL OUTCOME

\begin{tabular}{|l|c|c|c|c|}
\hline Variable & $\begin{array}{c}\text { No: of } \\
\text { cases }\end{array}$ & $\begin{array}{c}\text { Cases with } \\
\text { history of } \\
\text { addiction }\end{array}$ & $\begin{array}{c}\text { Percentage } \\
(\%)\end{array}$ & P-value \\
\hline $\begin{array}{l}\text { Perinatal } \\
\text { deaths }\end{array}$ & 260 & 170 & $66.15(n=260)$ & $<0.0001$ \\
\hline $\begin{array}{l}\text { Low birth } \\
\text { weight } \\
\text { infants }\end{array}$ & 169 & 120 & $71.00(n=169)$ & $<0.0001$ \\
\hline $\begin{array}{l}\text { Preterm } \\
\text { deliveries }\end{array}$ & 121 & 83 & $68.59(n=121)$ & $<0.0001$ \\
\hline
\end{tabular}




\section{DISCUSSION}

Maternal anemia has a varied prevalence, etiology and degree of severity among different population. The prevalence varies considerably because of differences in socio-economic conditions, life styles and health seeking behavior among different populations ${ }^{12}$.

Among the population of South East Asia, consumption of betel nut and its formulation is very common. The habit of chewing usually starts in school life and remains prevalent till adulthood ${ }^{8}$. There is substantial evidence that consuming betel nut formulation during pregnancy can lead to numerous health consequences including anemia, miscarriages and adverse fetal outcome ${ }^{7}$.

The epidemiological data pertaining to betel nut use in Pakistan has been reported in different subgroups and rates vary depending on the sample studied and the geographical area where the study was conducted ${ }^{13,14}$. The National Health Survey conducted in 1994 reported that $12.5 \%$ of Pakistani women use tobacco and among them $10 \%$ are using tobacco in any chewable form like Gutka, Naswar and $\mathrm{Pan}^{15}$. Senn $\mathrm{M}$ et al in their study reported a prevalence of $94 \%$ for betel nut chewing during pregnancy ${ }^{16}$. Patoli et al in their study found that $12 \%$ of women were consuming betel quid $^{17}$. Another study conducted in Karachi on a squatter settlement population reported that among female population $60.9 \%$ were Areca nut users and $56.5 \%$ were Gutka users ${ }^{18}$. Usman $G$ et al described in their study that $96 \%$ of women living in coastal area of Karachi consume Gutka while they breast feed their child ${ }^{19}$. In this study we found very high prevalence $(65.88 \%)$ of addiction of these substances in our pregnant women presented with anemia.

Several studies have documented the older maternal age as a risk factor for anemia in pregnancy ${ }^{20,21}$. In this study we also found increase frequency of anemia as the women's age and parity increase. Frequency of addiction was also high in older and multiparous women. This observation indicates the strong association of addiction with anemia.

Our study population included women from both urban area of Hyderabad city and rural area of Sindh Province. Frequency of addiction was more in rural population $(77.77 \%)$ as compared to urban population (55.05\%). A population based cohort study conducted in Pakistan reported the prevalence of anemia among married women aged $15-44$ to be $26 \%$ in urban areas and $47 \%$ in rural areas $^{22}$. In this study majority of women were presented with moderate degree of anemia. Frequency of addiction was found high in those presented with moderate anemia $(79.74 \%)$ and severe degree of anemia $(70 \%)$.

There are various studies that reported the association of severe anemia with preterm birth, low birth weight and small for gestational age fetus ${ }^{23-25}$. The existing studies suggest that betel nut chewing alone or with other ingredients have reproductive toxic potential ${ }^{26}$. Out of eight manuscripts that specifically examined the effects of betel nut use on pregnancy, seven have documented adverse effects on birth weight and pregnancy outcome ${ }^{9}$. It affects developing fetus both directly through passage of toxic material through placenta and indirectly through poor maternal health ${ }^{2}$. In this study adverse fetal outcome were fetal deaths, preterm deliveries and low birth weight infants. In these cases, there was positive history of addiction in $65.38 \%$ cases of fetal deaths, $70.58 \%$ cases of low birth weight infants and $66.68 \%$ cases of preterm deliveries. This study reported a high perinatal mortality because it included all the cases presented with intrauterine fetal deaths as well as those having early neonatal deaths due to prematurity and low birth weight

Limited research has been conducted to determine the consumption of betel nut and its products by our pregnant women and its consequences upon health. This study was undertaken primarily to find out the prevalence of consumption of betel nut products and secondarily to assess its impact on pregnancy outcome.

\section{CONCLUSION}

The results of this study suggest that consumption of betel nut products during pregnancy is strongly associated with anaemia in pregnancy which may adversely affects the developing fetus both directly and indirectly through poor maternal health. It is recommended that all pregnant women during their prenatal, antenatal, and postnatal periods should be provided with enough information and counseling regarding the potential ill health effects of betel nut products.

\section{REFERENCES}

1. Stevens GA, Finucane MM, De-Regil LM, Paciorek CJ, Flaxman SR, Branca F, et al. Global, regional, and national trends in haemoglobin concentration and prevalence of total and severe anaemia in children and pregnant and non-pregnant women for 1995-2011: a systematic analysis of population-representative data. Lancet Glob Health, 2013; 1(1): e16-25.

2. Geraldine U, Ndukwu, Paul O Dienye. Prevalence and Socio-demographic factors associated with anemia in pregnancy in a primary health center in Rivers State, Nigeria. Afr J of Prim Health Care Fam Med. 2012; 4(1): 328.

3. Sahu K.K, Idris M.Z, Agrawal M, Singh SK, Ali W, Shankar $P$, et al. Effects of anemia during third trimester of pregnancy on gestational size and birth weight of babies in rural Lucknow, India. World J Pharm Pharm Sci. 2013; 2(6): 4942-50.

4. Van den Broek N. Anemia in Pregnancy in developing countries. Br J of Obstet Gynaecol. 1998; 105(4):38590.

5. Patil V [Internet]. The world's most romantic leaf is heart shaped. E Sanskriti- The essence of Indian culture. Aug 2011. Available from: http://www.esamskriti.com/ e/ Culture/Indian-Culture/The-World-colon-S-MostRomantic-Leaf-Is-Heart Shaped-1.aspx.

6. Kader M. Association between betel nut consumption and folate deficiency among pregnant women in rural Bangladesh. Int J Med Public Health 2013; 3(2): 81-88.

7. Khan MS, Bawany FI, Shah SR, Hussain M, Arshad $\mathrm{MH}$, Nisar N. Comparison of knowledge, attitude and practices of betelnut users in two socio-economic areas of Karachi. JPak Med Assoc 2013; 63(10):1319-25.

8. Mirza SS, Shafique K, Vart P, Arian MI. Areca nut chewing and dependency syndrome : Is the dependence comparable to smoking? A cross sectional study. Subst Abuse TreatPrev Policy. 2011; 6: 23.

9. Chue $\mathrm{AL}$, Carrara VI, Paw MK, Pimanpanarak M, 
Wiladphaingern J, Van Vugt M, et al. Is Areca innocent? The effect of areca (betel) nut chewing in a population of pregnant women on the Thai-Myanmar border. Int. Health. Sept 2012; 4(3): 204-9.

10. Wikipedia[Internet]. Paan - Effects on Health. Available from: https://en.wikipedia.org/ wiki/Paan

11. Wolter Kluwer Health[Internet]. Betel nut: Uses, benefits and side effects. July 2009. St. Louis. MO. Available from: https://www.drugs.com/npc/betel-nut.html.

12. Lone FW, Qureshi RN, Emmanuel F. Maternal anemia and its impact on perinatal outcome in a tertiary care hospital in Pakistan. East Mediterr Health J. 2004; 10 (6): 801-6.

13. Rozi S, Akhtar S. Prevalence and predictors of smokeless tobacco use among high school males in Karachi Pakistan. East Mediterrr J. [online]. 2007; 13 (4): 916-924.

14. Shah SM, Merchant AT, Luby SP, Chotani RA. Addicted schoolchildren: Prevalence and characteristics of areca nut chewers among primary school children in Karachi, Pakistan. J Paediatr Child Health. 2002; 38(5): 507-10.

15. Jamali T, Tanzil S. Smokeless tobacco use among Pakistani women: A missed opportunity for tobacco control. J Coll Physicins Surg Pak. 2015; 25(4): 312.

16. Senn M, Baiwaq F, Winmai J, Mueller T, Rogerson S, Senn N. Betel nut chewing during pregnancy - Madang Province, Papua, New Guinea. Drug Alcohol Depend. 2009 Nov 1; 105(1-2): 126-31.

17. Patoli S, Jabeen N, Masood RT, Butt Al. Socioeconomic status and Smokeless tobacco consumption of fishermen community of a coastal area of Karachi. Annels of Abbasi Shaheed Hospital \& Karachi Medical \& Dental College. June 2015; 20(1):34-39.
18. Baig S, Mustafa M, Munazza, Rubab Z. Pattern of substance abuse in multi ethnic groups in different localities of Karachi. Pak J Med Dent. 2013; 1(1):47-54.

19. Usman G, Kumar S, Ashraf MI, Agha S, Taj A. Prevalence of Pan, Gutka, Betalnut, Naswar, and Cigarette smoking in University Students of Karachi. Med Forum 2015; 26(1): 41-44.

20. Alem M, Enawgaw B, Gelaw A, Kenaw T, Seid M, Olkeba $Y$. Prevalence of anaemia and associated risk factors among pregnant women attending antenatal care in Azizo Health centre Gonader town, Northwest Ethiopia. J Interdiscipl Histopathol 2013; 1(3):137-144.

21. Zhang Q, Li Z, Ananth CV. Prevalence and risk factors for anemia in pregnant women: a population based prospective cohort study in China. Paediatri Perinat Epidemiol 2009 July; 23(4): 282-291.

22. Pakistan Medical Research Council. National Health survey of Pakistan: Health profile of the people of Pakistan, 1990-1994. Islamabad Network Publications. 1998.

23. OGCCU. Antepartum care: complications in pregnancy. Clinical guidelines King Edward Memorial Hospital, March 2013. Available from: http:/l www.kemh.health.wa.gov.au/development/manuals/.

24. Haider BA, Olofin I, Wang M, Spiegelman D, Ezzati M, Fawzi WW, et al. Anemia, prenatal iron use and risk of adverse pregnancy outcomes: Systemic review and meta-analysis. BMJ 2013: 346:f3443

25. Yousuf F, Haider G, Shaikh RB, Haider A, Muhammad $\mathrm{N}$. Impact of maternal anemia on perinatal outcome. PAFMJ. Dec. 2011; 61(4).

26. Sahelian R. Betel nut health benefit and risk of chewing, side effects. 2016. Available from: www.raysahelian.com/betelnut.html.

AUTHOR AFFILIATION:
Dr. Farkhunda Khursheed (Corresponding Author)
Assistant Professor
Department of Obstetrics and Gynecology
Liaquat University of Medical and Health Sciences
(LUMHS), Jamshoro, Sindh -Pakistan.
Email: farkhunda11@hotmail.com
Dr. Chandra Madhudas
Assistant Professor
Department of Obstetrics and Gynecology
LUMHS, Jamshoro, Sindh -Pakistan.

